OPEN ACCESS

Edited by: Ute Hentschel,

GEOMAR - Helmholtz Centre for Ocean Research and University of Kiel, Germany

Reviewed by: Gwenael Piganeau, Centre National pour la Recherche Scientifique, France Julie Beth Olson,

The University of Alabama, USA

*Correspondence: Suhelen Egan s.egan@unsw.edu.au

Specialty section: This article was submitted to Microbial Symbioses, a section of the journal Frontiers in Microbiology

Received: 08 March 2016 Accepted: 09 June 2016

Published: 21 June 2016

Citation:

Egan S and Gardiner M (2016) Microbial Dysbiosis: Rethinking Disease in Marine Ecosystems. Front. Microbiol. 7:991. doi: 10.3389/fmicb.2016.00991

\section{Microbial Dysbiosis: Rethinking Disease in Marine Ecosystems}

\author{
Suhelen Egan* and Melissa Gardiner
}

Centre for Marine Bio-Innovation, School of Biological, Earth and Environmental Sciences, The University of New South Wales, Sydney, NSW, Australia

With growing environmental pressures placed on our marine habitats there is concern that the prevalence and severity of diseases affecting marine organisms will increase. Yet relative to terrestrial systems, we know little about the underlying causes of many of these diseases. Moreover, factors such as saprophytic colonizers and a lack of baseline data on healthy individuals make it difficult to accurately assess the role of specific microbial pathogens in disease states. Emerging evidence in the field of medicine suggests that a growing number of human diseases result from a microbiome imbalance (or dysbiosis), questioning the traditional view of a singular pathogenic agent. Here we discuss the possibility that many diseases seen in marine systems are, similarly, the result of microbial dysbiosis and the rise of opportunistic or polymicrobial infections. Thus, understanding and managing disease in the future will require us to also rethink definitions of disease and pathogenesis for marine systems. We suggest that a targeted, multidisciplinary approach that addresses the questions of microbial symbiosis in both healthy and diseased states, and at that the level of the holobiont, will be key to progress in this area.

Keywords: dysbiosis, marine diseases, opportunistic pathogens, microbial interactions, microbiome, holobiont

\section{INTRODUCTION}

Almost two decades on, the wealth of microbial biodiversity uncovered by the molecular ecology revolution continues to amaze. Microbiome studies are being reported at a rapid rate, and include ecosystems ranging from the deep oceans to the upper troposphere (DeLeon-Rodriguez et al., 2013; Inagaki et al., 2015). It is now widely accepted that microorganisms have important functions (albeit often not well understood), not only for our personal health, but also for the survival of our planet (Alivisatos et al., 2015).

In the marine environment, microorganisms constitute over $90 \%$ of the living biomass where they are essential for nutrient cycling and form intimate associations (symbiosis) with all other marine organisms. Microbial symbioses in marine environments can take many forms, and today one might argue that the excellent textbook cases of a single-symbiont to a single-host organism [e.g., Euprymna scolopes and Vibrio fischeri (McFall-Ngai, 2014)] are rare. Rather, most interactions between microorganisms and their host/s involve multiple partners that work in multifaceted ways to impact host development and physiology (Wahl et al., 2012), such as in the case for sponges (Webster and Thomas, 2016), corals (Rädecker et al., 2015), and algae (Egan et al., 2013; Abby et al., 2014; Amin et al., 2015).

However microbial-host interactions are not always beneficial and marine organisms are reported to suffer from a variety of disease symptoms, often as a result of a yet unknown etiology (Munn, 2006; Bourne et al., 2009; Gachon et al., 2010; Morado, 2011; Egan et al., 2014). Disease 
events in the marine environment not only impact directly on the host population, but can also result in ecosystem-wide impacts due to, for example, the mass mortality of keystone species (Burge et al., 2013). These events are predicted to increase with global climate change and elevating anthropogenic pressures (Gattuso et al., 2015). Hence, there is an urgent need to generate data that speak to both the causes and the environmental factors mitigating disease in marine systems. As a guide to understand the complexity of marine diseases, marine scientists may need to look to advances in the human microbiome field. In the past decade, research into human disease has suggested that many chronic diseases (including skin, bowel, and lung disorders) are driven by a disturbance (or shift) in the natural microbiome [i.e., dysbiosis (see Table 1 for definition)] rather than a singular etiological agent (Althani et al., 2015). Here, we propose that many diseases in marine systems can also be viewed from the point of microbial dysbiosis, analogous to some chronic diseases in humans. However, while a conceptual framework can be gained from studies of dysbiosis in the medical field, the nature of marine systems and the inherent differences between humans and marine organisms may necessitate a specific set of approaches and working models.

\section{ARE EMERGING DISEASES IN MARINE SYSTEMS RELATED TO DYSBIOSIS AND OPPORTUNISTIC PATHOGENS?}

The last decade has seen an increase in the reporting of disease syndromes of cultured and natural populations of marine organisms including fish, seagrass, seaweeds, corals, and other invertebrates (Harvell et al., 2002, 2004; Lafferty et al., 2004; Ward and Lafferty, 2004; Bourne et al., 2009; Gachon et al., 2010). However, in many cases the causative agent/s of the disease are unknown; and indeed debate over the importance of microbial pathogens in relatively wellstudied marine diseases continues (Hoegh-Guldberg et al., 2007; Rosenberg et al., 2009; Gachon et al., 2010; Burge et al., 2013).

The first likely explanation for the uncertainty over the microbial involvement in particular marine diseases is due to the difficulty in distinguishing pathogens from other saprophytic bacteria that proliferate on a diseased or decaying host (Burge et al., 2013; Egan et al., 2014). Adding to this uncertainty is the fact that in marine systems, without continued monitoring, it is often difficult to determine the early (and likely asymptomatic) stages of infection. Thus, it is possible that the commonly reported disease symptoms (e.g., bleaching, spotting, or rotting) for marine organisms are representative of late stages of disease and the proliferation of secondary invaders. Indeed, many features attributed to potential pathogen/s, such as the ability to colonize and degrade host tissue, could also be utilized by saprophytic organism/s, further obscuring the identity of the true primary pathogen/s.

A second explanation is that disease is not the result of a single microbial agent, but rather a consortium of microbial species (i.e., polymicrobial) with each member playing a distinct role in the pathogenic process. The black band disease (BBD) of corals is arguably, to date, the best model for polymicrobial disease in marine systems, with a complex microbial community consisting of cyanobacteria, heterotrophic and sulfur-cycling bacteria, as well as archaeal members implicated in disease progression (Sato et al., 2016).

TABLE 1 | Definition of terminology commonly used to describe microbial-host interactions in the context of host health and disease.

\begin{tabular}{|c|c|c|}
\hline Term & Definition & Further reading \\
\hline Commensal & $\begin{array}{l}\text { A host-associated organism that does not induce host damage upon } \\
\text { colonization }\end{array}$ & Casadevall and Pirofski, 2000 \\
\hline Disease & $\begin{array}{l}\text { The health outcome of an organism where normal function is impaired } \\
\text { after damage (often induced by a microbe(s)) has occurred. }\end{array}$ & Casadevall and Pirofski, 2003 \\
\hline Dysbiosis & A microbial community shift that has a negative impact on the host. & Petersen and Round, 2014 \\
\hline Holobiont & $\begin{array}{l}\text { A host organism and the entirety of its microbial community, under } \\
\text { normal conditions, and in the absence of disease. }\end{array}$ & Rosenberg et al., 2007 \\
\hline Koch's postulates & $\begin{array}{l}\text { A microorganism-centric methodology used to demonstrate a causal } \\
\text { relationship between a pathogen and a disease. The postulates } \\
\text { commonly cited are: the pathogen must be present in each case of the } \\
\text { disease and absent from healthy individuals; and when isolated in pure } \\
\text { culture and used to experimentally infect an individual, the pathogen } \\
\text { must induce the disease. }\end{array}$ & Kaufmann and Schaible, 2005 \\
\hline Opportunistic pathogen & $\begin{array}{l}\text { An organism that is capable of causing damage to a host under specific } \\
\text { conditions, but may also exist as a commensal on the same host. }\end{array}$ & Casadevall and Pirofski, 2000 \\
\hline Polymicrobial infection & Disease as a result of the co-infection by multiple microorganisms & Hajishengallis and Lamont, 2016 \\
\hline Saprophyte & $\begin{array}{l}\text { An organism that lives and proliferates on dead or already diseased } \\
\text { hosts. Often a secondary invader or opportunist. }\end{array}$ & Willey et al., 2008 \\
\hline Virulence & $\begin{array}{l}\text { A relative measure of a microorganism's ability to induce disease on a } \\
\text { host. }\end{array}$ & Méthot and Alizon, 2014 \\
\hline 'Dual role' virulence factor & $\begin{array}{l}\text { A microbial trait (molecule, protein, etc.) that has direct/indirect roles in } \\
\text { both environmental survival/persistence and host disease progression. }\end{array}$ & Vezzulli et al., 2008 \\
\hline
\end{tabular}


A third possibility is that some microbial pathogens exist as part of a host's native microbiome, and under certain conditions, i.e., host senesce, can switch from a commensal to a pathogenic lifestyle. For example, the marine bacterium Phaeobacter gallaeciensis BS107 produces antibacterial and growth promoting compounds that are beneficial to its host microalga, Emiliania huxleyi; however, upon detection of algal breakdown products, the beneficial bacterium is converted into an opportunistic pathogen through the production of algaecide compounds (Seyedsayamdost et al., 2011). In such cases it can be difficult to apply classical measurements of disease causality, such as Koch's postulates (see Table 1 for definition), which assume that the causative agent is always associated with disease while being completely absent in healthy individuals (Koch, 1882; Kaufmann and Schaible, 2005).

Finally, a forth and often overlooked explanation is that disease results from the proliferation of any number of opportunistic pathogens when there is dysbiosis in the host microbiome as a result of environmental pressures and/or host stress (Lesser et al., 2007; Burge et al., 2013; Egan et al., 2014) (Figure 1). Microbial dysbiosis has emerged as an explanation for several acute and chronic human diseases, including atopic dermatitis of the skin (Brüssow, 2015), gastrointestinal disorders (Clemente et al., 2012; Parekh et al., 2015), periodontal disease (Meyle and Chapple, 2015), and inflammatory respiratory diseases (Mahdavinia et al., 2016). In these examples, scientists and medical professionals suggest that a combination of environmental, immune, and host genetic immune factors, together with microbiome disturbance, play a role in the establishment and severity of these diseases (Legatzki et al., 2014; Butto et al., 2015; Donaldson et al., 2016; Hajishengallis and Lamont, 2016). For example, lower microbial diversity and depletion of commensal bacteria in the gut is associated with the development of asthma and Crohn's Disease, implicating a role for microbial dysbiosis in these now common diseases (Frank et al., 2007; Candela et al., 2012; Abrahamsson et al., 2014). Further, there is a growing appreciation for the complex interplay between beneficial species, opportunistic pathogens, environmental factors and the immune system, and the influence that these interactions have on human health outcomes, including the onset of chronic disease (Mazmanian et al., 2008; Chow and Mazmanian, 2010; Butto et al., 2015).

While less understood, there is evidence for dysbiosis syndromes in marine systems. Meres et al. (2012) proposed microbial dysbiosis and the emergence of opportunistic pathogens (including the previously reported Aquimarina spp. pathogens) as a mitigating factor in the epizootic shell disease (ESD) of lobsters. Likewise, analysis of microbial communities associated with healthy and diseased Montastraea corals indicated multiple etiological factors, including polymicrobial infections, are likely to be responsible for BBD (Miller and Richardson, 2015) and white-plague disease (Cook et al., 2013). Studies investigating the impact of environmental change on marine hosts have given further insight to the role of microbial dysbiosis and disease. Exposure to stressful environmental conditions results in distinct shifts in microbial community assemblages that can be detected prior to any physical sign

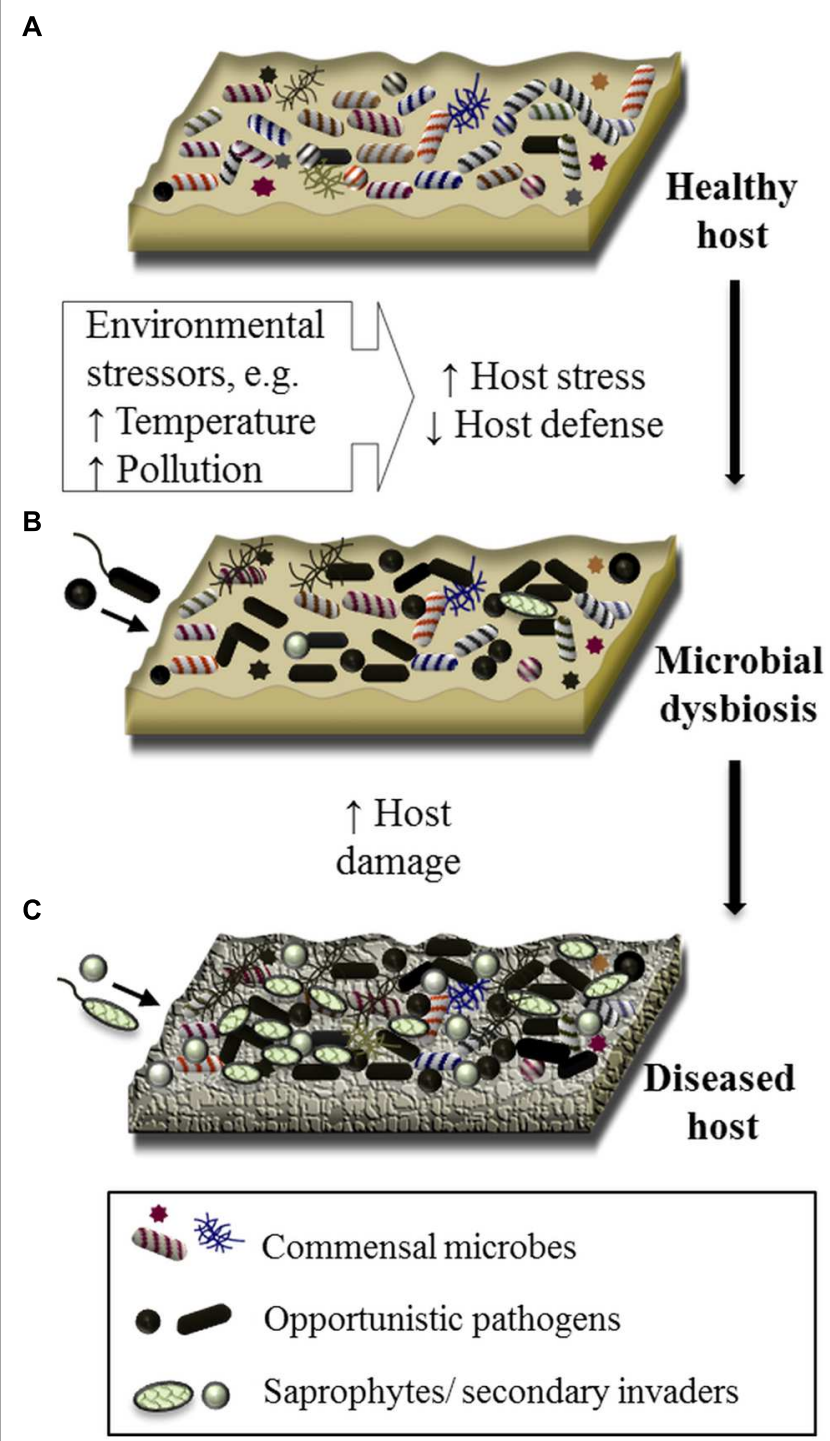

FIGURE 1 | Schematic of the proposed involvement of microbial dysbiosis, opportunistic pathogens and polymicrobial interactions in the disease of marine organisms. The surface of a healthy marine living organism (healthy host) is colonized by a consortium of commensal microorganisms, which may include bacteria, archaea, microbial eukaryotes, and viruses (A). Under conditions of elevated environmental pressure, the host can become stressed negatively impacting the host defence mechanisms. On this susceptible host, opportunistic pathogens and/or pathogenic consortia (i.e., polymicrobial infection), originating from the healthy host or from the surrounding environment, proliferate, resulting in a state of microbial dysbiosis (B). Microbial pathogens along with saprophytes or secondary colonizers further cause damage to the host resulting in visible disease (C).

of disease in corals (Webster et al., 2013; Closek et al., 2014), seaweeds (Fernandes et al., 2012; Stratil et al., 2013) and sponges (Webster et al., 2008; Fan et al., 2013) (Figure 1). In some cases, these shifts have been characterized by an increase in groups of pathogenic bacteria (e.g., Vibrio spp. (Tout et al., 2015), Roseobacter species (Zozaya-Valdes et al., 2015)) and/or an increase in the abundance of virulence-related functional genes 
(Vega Thurber et al., 2009; Littman et al., 2011; Fernandes et al., 2012). This may be considered early evidence for dysbiosis and the enrichment of bacteria with pathogenic potential. Thus, a disease framework centered around stress-induced dysbiosis and the emergence of opportunistic pathogens would not only explain inconsistencies in laboratory infection assays and pathogen detection in characterized diseases (e.g., Rosenberg et al., 2009; Meres et al., 2012; Cook et al., 2013; Joyner et al., 2015; Zozaya-Valdes et al., 2015), but would also help to understand the etiology of yet undefined syndromes.

\section{A CALL FOR A FRESH APPROACH TO CHARACTERIZE AND MANAGE MARINE DYSBIOSIS AND DISEASE}

Historically, studies of host-pathogen interactions have centered on the detection and control of the infectious agent/s. For decades researchers have studied the detailed molecular mechanisms that enable pathogenic microorganisms to infect their host and cause disease. These studies have resulted in a wealth of knowledge, including the identification of growth and virulence factors [e.g., toxins, enzymes, and host colonization factors (Finlay and Falkow, 1997)]. There is no doubt about the value of such an approach to disease control, especially where an understanding of pathogenesis has facilitated the development of vaccines and antibiotics to treat highly infectious pathogens such as those responsible for measles, diphtheria, and typhoid. However, if dysbiosis, opportunistic pathogens and/ or polymicrobial infections are responsible for disease, a paradigm shift in the way we think about host health and microbial symbiosis is required.

The importance of this paradigm shift has recently been recognized by medical microbiologists with calls to "ditch the term pathogen" (Casadevall and Pirofski, 2014; Altmann and Boyton, 2015) and to place greater emphasis on the complex interplay between the host and its microbiome (Méthot and Alizon, 2014). The importance of a less 'pathogen-centric' view of disease is now being recognized (Casadevall and Pirofski, 2015) and recent studies have also questioned the value of using common virulence genes alone as predictors of a bacterium's ability to cause disease (de Lorenzo, 2015; Hilker et al., 2015; Wassenaar and Gunzer, 2015). Indeed, many virulence traits in well-studied pathogens have secondary roles [or 'dual function roles' (see Table $\mathbf{1}$ for definition)] in persistence and stress adaptation outside the host environment (Casadevall et al., 2003; Vezzulli et al., 2008). Therefore, the discovery of a high proportion of virulence genes in the genomes of 'non-pathogenic' marine bacteria (Thomas et al., 2008; Persson et al., 2009; Gennari et al., 2012) and the dual function of known virulence factors (Erken et al., 2013; Gardiner et al., 2014) further speaks to the need for a broader contextual view of disease in the marine environment.

One of the first challenges in understanding the role of dysbiosis in marine diseases is obtaining suitable baseline data on what is considered a "healthy" microbiome. While the past decade has seen an increase in marine microbiome studies, inherent natural variation, inconsistency in sample collection and different approaches to data analysis means it is difficult to compare data across individual studies. Thus, there is an urgent need for larger spatial and temporal scale microbiome studies, particularly of species that are habitat-forming (e.g., macroalgae, corals), important to food security (e.g., farmed finfish and invertebrate species), or at high risk of disease (e.g., threatened or endangered species). For example, by analyzing the microbial diversity associated with over 250 samples covering a large spatial distribution of the reef forming kelp Ecklonia radiata, Marzinelli et al. (2015) identified a consistent microbiome for healthy individuals. However, when significant deviations in the kelp microbiome occurred, they could be correlated with visible signs of disease. Thus, with finer temporal sampling, microbial community data may be an effective environmental monitoring tool to detect microbiome changes as predictors for disease outcomes.

Despite the decreasing cost of characterizing microbial communities via sequencing, the scale required to adequately obtain the baseline data remains prohibitive to most individual research laboratories. Therefore, continued engagement of community and philanthropic supported initiatives will be essential. Such large scale microbiome initiatives have proven to be successful strategies for the analysis of oceanic microorganisms [e.g., GOS (Yooseph et al., 2007) and TARA (Pesant et al., 2015)], the human microbiome ${ }^{1}$ and other environmental systems [(e.g., Earth Microbiome Project ${ }^{2}$ (EMP)], with recent calls to move to an international microbiome initiative (IMI) that encompasses all habitats and is not limited by national boarders (Dubilier et al., 2015). We suggest that such global pattern analysis should be extended to include temporal studies of the typical microbiome of host species to gain insight into the emergence of dysbiosis and disease.

To accurately discover and manage the factors that contribute to dysbiosis and disease in marine systems requires a true holobiont approach (i.e., host and associated microbiome as one entity see Table 1). As stated above, such an approach needs to go beyond correlating health with the presence of specific groups of bacteria. Indeed, studies of vibriosis in oysters are finding that diseased animals are often colonized by diverse populations of Vibrio strains, rather than single virulent isolates (Lemire et al., 2015). Such findings further highlight the need to move beyond simple characterization of single pathogens and towards an understanding of how the host and its microbiome respond to, and interact with, each other, and how these interactions are influenced by environmental factors. Microbiologists, ecologists, environmental scientists, system biologists, and host physiologists will need to work closely together and occasionally step out of their comfort zone. For example, molecular microbiologists will need to become less reductionist and accept that the answers maybe more complex and variable than they feel confident with. Likewise (macro-) ecologists will need to embrace the concept that the organisms

\footnotetext{
${ }^{1}$ http://www.human-microbiome.org/

${ }^{2}$ http://www.earthmicrobiome.org/
} 
they study are not functioning on their own, but are influenced by millions of microorganisms that are not always simple to measure or control.

Compared to the medical field the understanding of dysbiosis in marine systems is in its infancy. In the last 10 years, over 1020 articles have been published on microbial dysbiosis in humans alone (using keywords "dysbiosis human", PubMed.gov search 10.02.16). However a similar search on marine organisms (using keywords "marine dysbiosis") retrieved only three publications. Whilst one can argue that the scientific breakthroughs in the medical field are due to the significantly larger research support (in terms of numbers of scientists and research funding), an important consideration is that this research effort is going towards one model organism, i.e., humans. This is in contrast to work on marine symbiosis, where relatively smaller amounts of money are spread across a large range of host species. Thus, in order for marine symbiosis research to come close to the equivalent depth of understanding of dysbiosis and disease as in the medical field, basic principles may need to first be studied collectively on fewer model species. The choice of model host/s should be made by the science community taking into consideration accessibility, ecological context, available metadata, as well as their ability to grow in aquaria and be experimentally manipulated. Indeed, some excellent marine model organisms exists to study microbial interactions and/or disease in macroalgae [e.g., Ectocarpus siliculosus (Zambounis et al., 2013) and Delisea pulchra (Harder et al., 2012)], invertebrates [e.g., oysters Crassostrea gigas (Le Roux et al., 2016); and cnidarians such as species of Aiptasia (Weis et al., 2008) and Hydra (Bosch, 2014)], vertebrates (e.g., zebrafish Danio rerio (Rawls et al., 2006), and medaka Oryzias latipes (Schartl, 2014)), and these systems should be further explored.

In addition it is important to consider how far the current theoretical framework of disease (predominately established for terrestrial systems) can be applied to marine systems. Indeed, McCallum et al. (2004) raised this question over 10 years ago and argued that, while the same theory may be applicable to marine systems, fundamental differences between marine and terrestrial systems may limit its usefulness. For example, marine systems will require their own set of disease models and management strategies that take into account the different life histories of marine and terrestrial organisms, the different modes of dispersal

\section{REFERENCES}

Abby, S. S., Touchon, M., De Jode, A., Grimsley, N., and Piganeau, G. (2014). Bacteria in Ostreococcus tauri cultures - friends, foes or hitchhikers? Front. Microbiol. 5:505. doi: 10.3389/fmicb.2014.00505

Abrahamsson, T. R., Jakobsson, H. E., Andersson, A. F., Bjorksten, B., Engstrand, L., and Jenmalm, M. C. (2014). Low gut microbiota diversity in early infancy precedes asthma at school age. Clin. Exp. Aller. 44, 842-850. doi: 10.1111/cea. 12253

Alivisatos, A. P., Blaser, M. J., Brodie, E. L., Chun, M., Dangl, J. L., Donohue, T. J., et al. (2015). Microbiome. A unified initiative to harness Earth's microbiomes. Science 350, 507-508. doi: 10.1126/science.aac 8480

Althani, A., Marei, H., Hamdi, W. S., Nasrallah, G. K., El Zowalaty, M. E., Al Khdor, S., et al. (2015). Human microbiome and its association with health and diseases. J. Cell. Physiol. 9999, 1-7. doi: 10.1002/jcp.25284 and recruitment of both microorganisms and their hosts (i.e., the "open" nature of marine systems), and differences in the impact of environmental change on marine and terrestrial systems (McCallum et al., 2004; Pollock et al., 2011; Arnold et al., 2012; Garren and Azam, 2012; Wahl et al., 2012; Burge et al., 2014).

\section{CONCLUSIONS AND PERSPECTIVES}

Ever since the early descriptions of the infectious agents by Robert Koch in the 1800s, the study of microbial diseases has been overshadowed by the desire to discover and eliminate the causative pathogen. However, as our understanding of microbial ecology and host-microbial interactions improve it is becoming increasingly clear that the relationship between a host and its microbiome is complex, and the lines between commensal microorganisms and pathogens are often blurred.

Next generation '-omic' technologies are living up to the promise of providing the data resolution and scale required to understand many of these complex interactions. However, major questions remain unanswered, including: How are microbiomes established and maintained? What specific functions do microbiomes play in host resilience, and how do changes in microbial community structure impact host health and disease? Answers to these questions and the need to rethink the definitions of disease are particularly pertinent to marine scientists today in the face of environmental change and increasing observations of disease inflicting marine organisms.

\section{AUTHOR CONTRIBUTIONS}

SE and MG both made a direct contribution to planning and writing of the manuscript and both have approved it for publication.

\section{ACKNOWLEDGMENTS}

The authors would like to thank the Australian Research Council and the Centre for Marine Bio-Innovation for research support. We also thank A/Prof. Torsten Thomas and Adam Bournazos for helpful discussion and editing of the final manuscript.

Altmann, D., and Boyton, R. (2015). Replace 'pathogens' with 'perceptogens.' Nature 518:35. doi: 10.1038/518035c

Amin, S. A., Hmelo, L. R., Van Tol, H. M., Durham, B. P., Carlson, L. T., Heal, K. R., et al. (2015). Interaction and signalling between a cosmopolitan phytoplankton and associated bacteria. Nature 522, 98-101. doi: 10.1038/nature14488

Arnold, T., Mealey, C., Leahey, H., Miller, A. W., Hall-Spencer, J. M., Milazzo, M., et al. (2012). Ocean acidification and the loss of phenolic substances in marine plants. PLoS ONE 7:e35107. doi: 10.1371/journal.pone.0035107

Bosch, T. C. G. (2014). Rethinking the role of immunity: lessons from Hydra. Trends Immunol. 35, 495-502. doi: 10.1016/j.it.2014.07.008

Bourne, D. G., Garren, M., Work, T. M., Rosenberg, E., Smith, G. W., and Harvell, C. D. (2009). Microbial disease and the coral holobiont. Trends Microbiol. 17, 554-562. doi: 10.1016/j.tim.2009.09.004

Brüssow, H. (2015). Turning the inside out: the microbiology of atopic dermatitis. Environ. Microbiol. Advan. doi: 10.1111/1462-2920.13050 [Epub ahead of print]. 
Burge, C. A., Eakin, C. M., Friedman, C. S., Froelich, B., Hershberger, P. K., Hofmann, E. E., et al. (2014). "Climate change influences on marine infectious diseases: Implications for management and society," in Annual Review of Marine Science, Vol. 6, eds C. A. Carlson and S. J. Giovannoni (Palo Alto, CA: Annual Reviews), 249-277.

Burge, C. A., Kim, C. J. S., Lyles, J. M., and Harvell, C. D. (2013). Special issue oceans and humans health: the ecology of marine opportunists. Microb. Ecol. 65, 869-879. doi: 10.1007/s00248-013-0190-7

Butto, L. F., Schaubeck, M., and Haller, D. (2015). Mechanisms of microbehost interaction in Crohn's disease: dysbiosis vs. Pathobiont selection. Front. Immunol. 6:555. doi: 10.3389/fimmu.2015.00555

Candela, M., Rampelli, S., Turroni, S., Severgnini, M., Consolandi, C., De Bellis, G., et al. (2012). Unbalance of intestinal microbiota in atopic children. BMC Microbiol. 12:95. doi: 10.1186/1471-2180-12-95

Casadevall, A., and Pirofski, L. A. (2000). Host-pathogen interactions: basic concepts of microbial commensalism, colonization, infection, and disease. Infect. Immun. 68, 6511-6518. doi: 10.1128/iai.68.12.6511-6518.2000

Casadevall, A., and Pirofski, L. A. (2003). The damage-response framework of microbial pathogenesis. Nat. Rev. Microbiol. 1, 17-24. doi: 10.1038/nrmicro732

Casadevall, A., and Pirofski, L. A. (2014). Ditch the term pathogen. Nature 516, 165-166. doi: 10.1038/516165a

Casadevall, A., and Pirofski, L. A. (2015). What is a host? Incorporating the microbiota into the damage-response framework. Infect. Immun. 83, 2-7. doi: 10.1128/iai.02627-14

Casadevall, A., Steenbergen, J. N., and Nosanchuk, J. D. (2003). 'Ready made' virulence and 'dual use' virulence factors in pathogenic environmental fungi the Cryptococcus neoformans paradigm. Curr. Opin. Microbiol. 6, 332-337. doi: 10.1016/s1369-5274(03)00082-1

Chow, J., and Mazmanian, S. K. (2010). A pathobiont of the microbiota balances host colonization and intestinal inflammation. Cell Host Microbe 7, 265-276. doi: 10.1016/j.chom.2010.03.004

Clemente, J. C., Ursell, L. K., Parfrey, L. W., and Knight, R. (2012). The impact of the gut microbiota on human health: an integrative view. Cell 148, 1258-1270. doi: 10.1016/j.cell.2012.01.035

Closek, C. J., Sunagawa, S., Desalvo, M. K., Piceno, Y. M., Desantis, T. Z., Brodie, E. L., et al. (2014). Coral transcriptome and bacterial community profiles reveal distinct yellow band disease states in Orbicella faveolata. ISME J. 8, 2411-2422. doi: 10.1038/ismej.2014.85

Cook, G. M., Rothenberger, J. P., Sikaroodi, M., Gillevet, P. M., Peters, E. C., and Jonas, R. B. (2013). A comparison of culture-dependent and cultureindependent techniques used to characterize bacterial communities on healthy and white plague-diseased corals of the Montastraea annularis species complex. Coral Reefs 32, 375-388. doi: 10.1007/s00338-012-0989-6

de Lorenzo, V. (2015). Pseudomonas aeruginosa: the making of a pathogen. Environ. Microbiol. 17, 1-3. doi: 10.1111/1462-2920.12620

DeLeon-Rodriguez, N., Lathem, T. L., Rodriguez, R. L., Barazesh, J. M., Anderson, B. E., Beyersdorf, A. J., et al. (2013). Microbiome of the upper troposphere: species composition and prevalence, effects of tropical storms, and atmospheric implications. Proc. Natl. Acad. Sci. U.S.A. 110, 2575-2580. doi: 10.1073/pnas.1212089110

Donaldson, G. P., Lee, S. M., and Mazmanian, S. K. (2016). Gut biogeography of the bacterial microbiota. Nat. Rev. Microbiol. 14, 20-32. doi: 10.1038/nrmicro3552

Dubilier, N., Mcfall-Ngai, M., and Zhao, L. (2015). Create a global microbiome effort. Nature 526, 631-634. doi: 10.1038/526631a

Egan, S., Fernandes, N. D., Kumar, V., Gardiner, M., and Thomas, T. (2014). Bacterial pathogens, virulence mechanism and host defence in marine macroalgae. Environ. Microbiol. 16, 925-938. doi: 10.1111/1462-2920. 12288

Egan, S., Harder, T., Burke, C., Steinberg, P., Kjelleberg, S., and Thomas, T. (2013). The seaweed holobiont: understanding seaweed-bacteria interactions. FEMS Microbiol. Rev. 37, 462-476. doi: 10.1111/1574-6976.12011

Erken, M., Lutz, C., and Mcdougald, D. (2013). The rise of pathogens: predation as a factor driving the evolution of human pathogens in the environment. Microb. Ecol. 65, 860-868. doi: 10.1007/s00248-013-0189-0

Fan, L., Liu, M., Simister, R., Webster, N. S., and Thomas, T. (2013). Marine microbial symbiosis heats up: the phylogenetic and functional response of a sponge holobiont to thermal stress. ISME J. 7, 991-1002. doi: 10.1038/ismej.2012.165
Fernandes, N., Steinberg, P., Rusch, D., Kjelleberg, S., and Thomas, T. (2012). Community structure and functional gene profile of bacteria on healthy and diseased thalli of the red seaweed Delisea pulchra. PLoS ONE 7:e50854. doi: 10.1371/journal.pone.0050854

Finlay, B. B., and Falkow, S. (1997). Common themes in microbial pathogenicity revisited. Microbiol. Mol. Biol. Rev. 61, 136-169.

Frank, D. N., Amand, A. L. S., Feldman, R. A., Boedeker, E. C., Harpaz, N., and Pace, N. R. (2007). Molecular-phylogenetic characterization of microbial community imbalances in human inflammatory bowel diseases. Proc. Natl. Acad. Sci. U.S.A. 104, 13780-13785. doi: 10.1073/pnas.0706625104

Gachon, C. M. M., Sime-Ngando, T., Strittmatter, M., Chambouvet, A., and Kim, G. H. (2010). Algal diseases: spotlight on a black box. Trends Plant Sci. 15, 633-640. doi: 10.1016/j.tplants.2010.08.005

Gardiner, M., Hoke, D. E., and Egan, S. (2014). An ortholog of the Leptospira interrogans lipoprotein LipL32 aids in the colonization of Pseudoalteromonas tunicata to host surfaces. Front. Microbiol. 5:323. doi: 10.3389/fmicb.2014.00323

Garren, M., and Azam, F. (2012). New directions in coral reef microbial ecology. Environ. Microbiol. 14, 833-844. doi: 10.1111/j.1462-2920.2011.02597.x

Gattuso, J. P., Magnan, A., Bille, R., Cheung, W. W. L., Howes, E. L., Joos, F., et al. (2015). Contrasting futures for ocean and society from different anthropogenic $\mathrm{CO}_{2}$ emissions scenarios. Science 349, 45-55. doi: 10.1126/science.aac4722

Gennari, M., Ghidini, V., Caburlotto, G., and Lleo, M. M. (2012). Virulence genes and pathogenicity islands in environmental Vibrio strains nonpathogenic to humans. FEMS Microbiol. Ecol. 82, 563-573. doi: 10.1111/j.15746941.2012.01427.x

Hajishengallis, G., and Lamont, R. J. (2016). Dancing with the stars: how choreographed bacterial interactions dictate nososymbiocity and give rise to keystone pathogens, accessory pathogens, and pathobionts. Trends Microbiol. Adv. 24, 477-489. doi: 10.1016/j.tim.2016.02.010

Harder, T., Campbell, A. H., Egan, S., and Steinberg, P. D. (2012). Chemical mediation of ternary interactions between marine holobionts and their environment as exemplified by the red alga Delisea pulchra. J. Chem. Ecol. 38, 442-450. doi: 10.1007/s10886-012-0119-5

Harvell, C. D., Mitchell, C. E., Ward, J. R., Altizer, S., Dobson, A. P., Ostfeld, R. S., et al. (2002). Ecology - Climate warming and disease risks for terrestrial and marine biota. Science 296, 2158-2162. doi: 10.1126/science. 10 63699

Harvell, D., Aronson, R., Baron, N., Connell, J., Dobson, A., Ellner, S., et al. (2004). The rising tide of ocean diseases: unsolved problems and research priorities. Front. Ecol. Environ. 2:375-382. doi: 10.2307/3868363

Hilker, R., Munder, A., Klockgether, J., Losada, P. M., Chouvarine, P., Cramer, N., et al. (2015). Interclonal gradient of virulence in the Pseudomonas aeruginosa pangenome from disease and environment. Environ. Microbiol. 17, 29-46. doi: $10.1111 / 1462-2920.12606$

Hoegh-Guldberg, O., Mumby, P. J., Hooten, A. J., Steneck, R. S., Greenfield, P., Gomez, E., et al. (2007). Coral reefs under rapid climate change and ocean acidification. Science 318, 1737-1742. doi: 10.1126/science.11 52509

Inagaki, F., Hinrichs, K. U., Kubo, Y., Bowles, M. W., Heuer, V. B., Hong, W. L., et al. (2015). Deep biosphere. Exploring deep microbial life in coal-bearing sediment down to $\sim 2.5 \mathrm{~km}$ below the ocean floor. Science 349, 420-424. doi: $10.1126 /$ science.aaa6882

Joyner, J. L., Sutherland, K. P., Kemp, D. W., Berry, B., Griffin, A., Porter, J. W., et al. (2015). Systematic analysis of white pox disease in acropora palmata of the florida keys and role of Serratia marcescens. Appl. Environ. Microbiol. 81, 4451-4457. doi: 10.1128/aem.00116-15

Kaufmann, S. H., and Schaible, U. E. (2005). 100th anniversary of robert koch's nobel prize for the discovery of the tubercle bacillus. Trends Microbiol. 13, 469-475. doi: 10.1016/j.tim.2005.08.003

Koch, R. (1882). Die aetiologie der tuberculose (Nach einem in der physiologischen Gesellschaft zu Berlin am 24.März cr. gehaltenem Vortrage). Berl. Klin. Wochenschr. 19:221.

Lafferty, K. D., Porter, J. W., and Ford, S. E. (2004). Are diseases increasing in the ocean? Annu. Rev. Ecol. Evol. Syst. 35, 31-54. doi: 10.1146/annurev.ecolsys.35.021103.105704

Le Roux, F., Wegner, K. M., and Polz, M. F. (2016). Oysters and Vibrios as a model for disease dynamics in wild animals. Trends Microbiol. Adv. doi: 10.1016/j.tim.2016.03.006 [Epub ahead of print]. 
Legatzki, A., Rosler, B., and Von Mutius, E. (2014). Microbiome diversity and asthma and allergy risk. Curr. Allergy Asthma Rep. 14:466. doi: 10.1007/s11882014-0466-0

Lemire, A., Goudenège, D., Versigny, T., Petton, B., Calteau, A., Labreuche, Y., et al. (2015). Populations, not clones, are the unit of Vibrio pathogenesis in naturally infected oysters. ISME J. 9, 1523-1531. doi: 10.1038/ismej. 2014.233

Lesser, M. P., Bythell, J. C., Gates, R. D., Johnstone, R. W., and Hoegh-Guldberg, O. (2007). Are infectious diseases really killing corals? Alternative interpretations of the experimental and ecological data. J. Exp. Mar. Biol. Ecol. 346, 36-44. doi: 10.1016/j.jembe.2007.02.015

Littman, R., Willis, B. L., and Bourne, D. G. (2011). Metagenomic analysis of the coral holobiont during a natural bleaching event on the Great Barrier Reef. Environ. Microbiol. Rep. 3, 651-660. doi: 10.1111/j.1758-2229.2010. 00234.x

Mahdavinia, M., Keshavarzian, A., Tobin, M. C., Landay, A. L., and Schleimer, R. P. (2016). A comprehensive review of the nasal microbiome in chronic rhinosinusitis (CRS). Clin. Exp. Aller. 46, 21-41. doi: 10.1111/cea. 12666

Marzinelli, E. M., Campbell, A. H., Valdes, E. Z., Verges, A., Nielsen, S., Wernberg, T., et al. (2015). Continental-scale variation in seaweed hostassociated bacterial communities is a function of host condition, not geography. Environ. Microbiol. 17, 4078-4088. doi: 10.1111/1462-2920. 12972

Mazmanian, S. K., Round, J. L., and Kasper, D. L. (2008). A microbial symbiosis factor prevents intestinal inflammatory disease. Nature 453, 620-625. doi: 10.1038 /nature 07008

McCallum, H. I., Kuris, A., Harvell, C. D., Lafferty, K. D., Smith, G. W., and Porter, J. (2004). Does terrestrial epidemiology apply to marine systems? Trends Ecol. Evol. 19, 585-591. doi: 10.1016/j.tree.2004. 08.009

McFall-Ngai, M. J. (2014). “The importance of microbes in animal development: lessons from the squid-Vibrio symbiosis," in Annual Review of Microbiology, ed. S. Gottesman (Palo Alto, CA: Annual Reviews), 177-194.

Meres, N. J., Ajuzie, C. C., Sikaroodi, M., Vemulapalli, M., Shields, J. D., and Gillevet, P. M. (2012). Dysbiosis in epizootic shell disease of the American lobster (Homarus americanus). J. Shellfish Res. 31, 463-472. doi: 10.2983/035.031.0206

Méthot, P. O., and Alizon, S. (2014). What is a pathogen? Toward a process view of host-parasite interactions. Virulence 5, 775-785. doi: $10.4161 / 21505594.2014 .960726$

Meyle, J., and Chapple, I. (2015). Molecular aspects of the pathogenesis of periodontitis. Periodontol 2000, 7-17. doi: 10.1111/prd. 12104

Miller, A. W., and Richardson, L. L. (2015). Emerging coral diseases: a temperaturedriven process? Mar. Ecol. 36, 278-291. doi: 10.1111/maec.12142

Morado, J. F. (2011). Protistan diseases of commercially important crabs: a review. J. Invertebr. Pathol. 106, 27-53. doi: 10.1016/j.jip.2010.09.014

Munn, C. B. (2006). Viruses as pathogens of marine organisms - from bacteria to whales. J. Mar. Biol. Assoc. 86, 453-467. doi: 10.1017/s0025315406 $01335 \mathrm{x}$

Parekh, P. J., Balart, L. A., and Johnson, D. A. (2015). The influence of the gut microbiome on obesity, metabolic syndrome and gastrointestinal disease. Clin. Transl. Gastroenterol. 6:e91. doi: 10.1038/ctg.2015.16

Persson, O. P., Pinhassi, J., Riemann, L., Marklund, B. I., Rhen, M., Normark, S., et al. (2009). High abundance of virulence gene homologues in marine bacteria. Environ. Microbiol. 11, 1348-1357. doi: 10.1111/j.1462-2920.2008. 01861.x

Pesant, S., Not, F., Picheral, M., Kandels-Lewis, S., Le Bescot, N., Gorsky, G., et al. (2015). Open science resources for the discovery and analysis of Tara Oceans data. Sci. Data 2, 150023-150023. doi: 10.1038/sdata. 2015.23

Petersen, C., and Round, J. L. (2014). Defining dysbiosis and its influence on host immunity and disease. Cell. Microbiol. 16, 1024-1033. doi: 10.1111/cmi. 12308

Pollock, F. J., Morris, P. J., Willis, B. L., and Bourne, D. G. (2011). The urgent need for robust coral disease diagnostics. PLoS Pathog. 7:e1002183. doi: 10.1371/journal.ppat.1002183
Rädecker, N., Pogoreutz, C., Voolstra, C. R., Wiedenmann, J., and Wild, C. (2015). Nitrogen cycling in corals: the key to understanding holobiont functioning? Trends Microbiol. 23, 490-497. doi: 10.1016/j.tim.2015.03.008

Rawls, J. F., Mahowald, M. A., Ley, R. E., and Gordon, J. I. (2006). Reciprocal gut microbiota transplants from zebrafish and mice to germ-free recipients reveal host habitat selection. Cell 127, 423-433. doi: 10.1016/j.cell.2006.08.043

Rosenberg, E., Koren, O., Reshef, L., Efrony, R., and Zilber-Rosenberg, I. (2007). The role of microorganisms in coral health, disease and evolution. Nat. Rev. Microbiol. 5, 355-362. doi: 10.1038/nrmicro1635

Rosenberg, E., Kushmaro, A., Kramarsky-Winter, E., Banin, E., and Yossi, L. (2009). The role of microorganisms in coral bleaching. ISME J. 3, 139-146. doi: 10.1038/ismej.2008.104

Sato, Y., Civiello, M., Bell, S. C., Willis, B. L., and Bourne, D. G. (2016). Integrated approach to understanding the onset and pathogenesis of black band disease in corals. Environ. Microbiol. 18, 752-765. doi: 10.1111/1462-2920.13122

Schartl, M. (2014). Beyond the zebrafish: diverse fish species for modeling human disease. Dis. Model. Mech. 7, 181-192. doi: 10.1242/dmm.012245

Seyedsayamdost, M. R., Case, R. J., Kolter, R., and Clardy, J. (2011). The Jekylland-hyde chemistry of Phaeobacter gallaeciensis. Nat. Chem. 3, 331-335. doi: 10.1038/nchem.1002

Stratil, S. B., Neulinger, S. C., Knecht, H., Friedrichs, A. K., and Wahl, M. (2013). Temperature-driven shifts in the epibiotic bacterial community composition of the brown macroalga Fucus vesiculosus. Microbiologyopen 2, 338-349. doi: 10.1002/mbo3.79

Thomas, T., Evans, F. F., Schleheck, D., Mai-Prochnow, A., Burke, C., Penesyan, A., et al. (2008). Analysis of the Pseudoalteromonas tunicata genome reveals properties of a surface-associated life style in the marine environment. PLoS ONE 3:e3252. doi: 10.1371/journal.pone.0003252

Tout, J., Siboni, N., Messer, L. F., Garren, M., Stocker, R., Webster, N. S., et al. (2015). Increased seawater temperature increases the abundance and alters the structure of natural Vibrio populations associated with the coral Pocillopora damicornis. Front. Microbiol. 6:432. doi: 10.3389/fmicb.2015. 00432

Vega Thurber, R., Willner-Hall, D., Rodriguez-Mueller, B., Desnues, C., Edwards, R. A., Angly, F., et al. (2009). Metagenomic analysis of stressed coral holobionts. Environ. Microbiol. 11, 2148-2163. doi: 10.1111/j.1462-2920.2009. 01935.x

Vezzulli, L., Guzman, C. A., Colwell, R. R., and Pruzzo, C. (2008). Dual role colonization factors connecting Vibrio cholerae's lifestyles in human and aquatic environments open new perspectives for combating infectious diseases. Curr. Opin. Biotechnol. 19, 254-259. doi: 10.1016/j.copbio.2008.04.002

Wahl, M., Goecke, F., Labes, A., Dobretsov, S., and Weinberger, F. (2012). The second skin: ecological role of epibiotic biofilms on marine organisms. Front. Microbiol. 3:292. doi: 10.3389/fmicb.2012.00292

Ward, J. R., and Lafferty, K. D. (2004). The elusive baseline of marine disease: are diseases in ocean ecosystems increasing? PLoS Biol. 2:E120. doi: 10.1371/journal.pbio.0020120

Wassenaar, T. M., and Gunzer, F. (2015). The prediction of virulence based on presence of virulence genes in E. coli may not always be accurate. Gut Pathog. 7:15. doi: 10.1186/s13099-015-0062-4

Webster, N. S., Cobb, R. E., and Negri, A. P. (2008). Temperature thresholds for bacterial symbiosis with a sponge. ISME J. 2, 830-842. doi: 10.1038/ismej.2008.42

Webster, N. S., Negri, A. P., Flores, F., Humphrey, C., Soo, R., Botte, E. S., et al. (2013). Near-future ocean acidification causes differences in microbial associations within diverse coral reef taxa. Environ. Microbiol. Rep. 5, 243-251. doi: 10.1111/1758-2229.12006

Webster, N. S., and Thomas, T. (2016). The sponge hologenome. mBio 7:e00135. doi: $10.1128 / \mathrm{mBio} .00135-16$

Weis, V. M., Davy, S. K., Hoegh-Guldberg, O., Rodriguez-Lanetty, M., and Pringe, J. R. (2008). Cell biology in model systems as the key to understanding corals. Trends Ecol. Evol. 23, 369-376. doi: 10.1016/j.tree.2008. 03.004

Willey, J. M., Sherwood, L., Woolverton, C. J., and Prescott, L. M. (2008). Prescott, Harley, and Klein's Microbiology. New York, NY: McGraw-Hill Higher Education.

Yooseph, S., Sutton, G., Rusch, D. B., Halpern, A. L., Williamson, S. J., Remington, K., et al. (2007). The sorcerer II global ocean sampling 
expedition: expanding the universe of protein families. PLoS Biol. 5:e16. doi: 10.1371/journal.pbio.0050016

Zambounis, A., Strittmatter, M., and Gachon, C. M. M. (2013). Chronic stress and disease resistance in the genome model marine seaweed Ectocarpus siliculosus. Aquat. Bot. 104, 147-152. doi: 10.1016/j.aquabot.2012. 07.008

Zozaya-Valdes, E., Egan, S., and Thomas, T. (2015). A comprehensive analysis of the microbial communities of healthy and diseased marine macroalgae and the detection of known and potential bacterial pathogens. Front. Microbiol. 6:146. doi: $10.3389 /$ fmicb.2015.00146
Conflict of Interest Statement: The authors declare that the research was conducted in the absence of any commercial or financial relationships that could be construed as a potential conflict of interest.

Copyright (C) 2016 Egan and Gardiner. This is an open-access article distributed under the terms of the Creative Commons Attribution License (CC BY). The use, distribution or reproduction in other forums is permitted, provided the original author(s) or licensor are credited and that the original publication in this journal is cited, in accordance with accepted academic practice. No use, distribution or reproduction is permitted which does not comply with these terms. 